
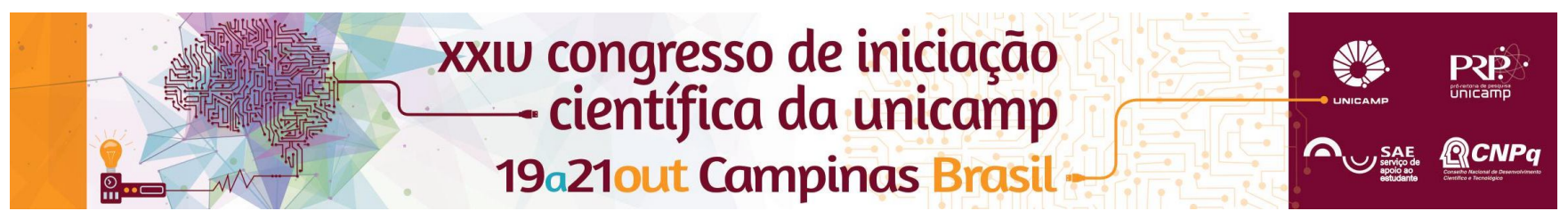

\title{
Reciclagem de gesso de construção e fosfogesso
}

\author{
João R. R. Soares*, Beatriz O. Felício*, Gustavo E. S. Amorim, Sara B. Ferreira, Rodrigo H. Geraldo, Gladis \\ Camarini.
}

\section{Resumo}

O objetivo do trabalho foi investigar a viabilidade da aplicação do gesso reciclado e do fosfogesso na construção civil, em especial na produção de componentes para alvenaria de vedação. Foram avaliados o gesso reciclado e o fosfogesso calcinados em três temperaturas: $150^{\circ} \mathrm{C}, 180^{\circ} \mathrm{C}$ e $200^{\circ} \mathrm{C}$. Foram avaliados os tempos de pega (Vicat), dureza e resistência à compressão. Os resultados indicaram que o fosfogesso calcinado a $180^{\circ} \mathrm{C}$ e o gesso reciclado a $200{ }^{\circ} \mathrm{C}$ apresentaram melhores resultados, sendo o fosfogesso o de melhor desempenho mecânico. Os resultados indicam que é possível utilizar o fosfogesso e o gesso reciclado como material para confecção de componentes.

\section{Palavras-chave:}

fosfogesso, gesso reciclado, resistência à compressão, dureza, tempos de pega.

\section{Introdução}

A construção civil é responsável por mais de $50 \%$ de geração de lixo ${ }^{1}$. Diante de sua responsabilidade para diminuir os danos causados ao meio ambiente a pesquisa procurou investigar a viabilidade técnica do uso de resíduos como matéria prima para construção civil.

O objetivo é avaliar as se o fosfogesso pode ser reciclável e apresenta propriedades semelhantes ao do gesso reciclável.

O fosfogesso, também conhecido como gesso químico, é um subproduto da fabricação de ácido fosfórico (P2O5), matéria-prima para a produção de fertilizantes fosfatados. Para cada tonelada de ácido fosfórico são geradas 4 a 6 toneladas de fosfogesso ${ }^{2}$. Atualmente no Brasil o fosfogesso é um passivo ambiental que é descartado e não reaproveitado.

Considerando as potencialidades técnicas dos dois resíduos: gesso reciclado e fosfogesso foi desenvolvido um estudo com o objetivo de avaliar a viabilidade da reciclagem do fosfogesso na substituição ao gesso da construção civil e comparar os resultados com os obtidos pelo gesso reciclado.

\section{Materiais e Métodos}

O gesso e o fosfogesso foram calcinados em três temperaturas: $150^{\circ} \mathrm{C}, 180^{\circ} \mathrm{C}$ e $200^{\circ} \mathrm{C}$ e os resultados foram comparados com a norma Brasileira para gesso de construção ${ }^{3}$. Foram realizados os ensaios de tempo de pega por meio do aparelho Vicat, resistência à compressão e dureza.

\section{Resultados e Discussão}

Os resultados de resistência à compressão (Figura 1) foram melhores para o fosfogesso reciclado a $180{ }^{\circ} \mathrm{C}$ $(11,56)$ e para o gesso reciclado a $200{ }^{\circ} \mathrm{C}(7,03 \mathrm{MPa})$. Os melhores resultados de dureza (Figura 2) foram para o fosfogesso calcinado a $200^{\circ} \mathrm{C}(35,96 \mathrm{Mpa})$ e para 0 gesso reciclado a $180^{\circ} \mathrm{C}(21,2 \mathrm{MPa})$. Somente 0 fosfogesso está dentro dos limites estabelecidos pela norma ${ }^{3}$.

Além disso, os resultados de resistência à compressão indicam que são superiores ao mínimo exigido para componentes de alvenaria de vedação (>2,2 MPa).

Em relação aos tempos de pega, todas as amostras tiveram valores de início de pega acima do valor mínimo da norma, porém não satisfizeram todas com resultados inferiores ao mínimo tempo de fim de pega. Com um tempo de pega adequado, é possível realizar a moldagem dos componentes para alvenaria de vedação.

Figura 1. Resultados de resistência à compressão

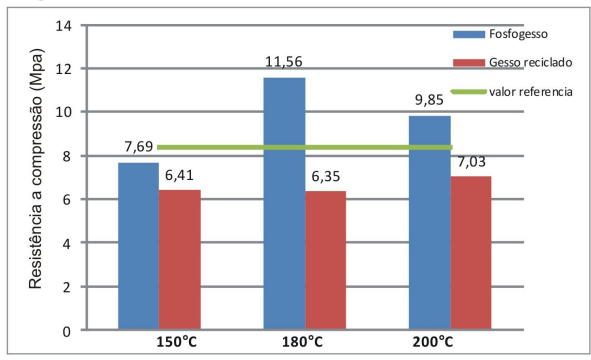

Figura 2. Resultados da dureza das pastas.

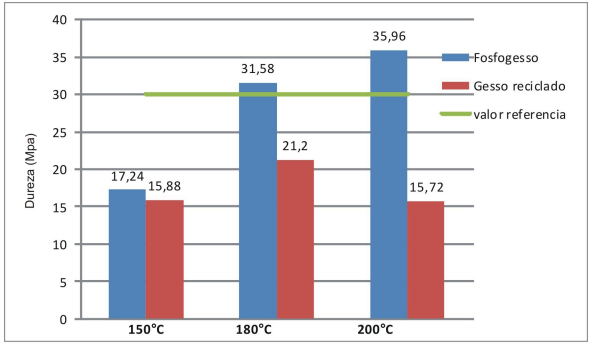

\section{Conclusões}

Os resultados indicaram a possibilidade de uso do gesso e o fosfogesso reciclados na construção civil, particularmente em blocos de vedação.

\section{Agradecimentos}

Ao CNPq, à CAPES, à Faculdade de Engenharia Civil, Arquitetura e Urbanismo, FEC-UNICAMP, ao IFSULDEMINAS- Poços de Caldas.

[1] Ângulo, S. C. Variabilidade de agregados graúdos de resíduos de construção e demolição reciclados. 2000. 155p. Dissertação (Mestrado) - Escola Politécnica da Universidade de São Paulo, São Paulo.

[2] Nuernberg, N.J.; Rech, T.D; Basso, C. Uso do gesso agrícola. BOLETIM TÉCNICO n. 122 Empresa de Pesquisa Agropecuária e Extensão Rural de Santa Catarina S.A (EPAGRI). Santa Catarina: EPAGRI, 2005.

[3] Associação Brasileira de Normas Técnicas- NBR 13207 - MB 3471.Gesso para Construção - Determinação das propriedades mecânicas. Rio de Janeiro, $1994 c$ 